\title{
O PATRIMÔNIO HISTÓRICO COMO LUGAR SOCIAL
}

\section{The historical heritage as social place}

\author{
Silmara Dias FEIBER ${ }^{1}$
}

\section{RESUMO}

A presente investigação procura compreender as funções do "lugar" na formação de identidades e analisa, neste contexto, especificamente a função do Patrimônio Histórico e Cultural na época atual. Toma, como exemplo, o caso de uma Igreja de madeira no Interior do Estado do Paraná, a Igreja de Nossa Senhora de Fátima que foi erguida originalmente, em 1958, no distrito São João D'Oeste e depois transferida, em 1987, para a sede do município de Cascavel/PR.

Palavras-chave: lugar; patrimônio histórico; semiótica; significação; Cascavel-PR.

\begin{abstract}
This research focuses on the role of "Place" in identity formation and it analyzes, specifically the function of historical and cultural heritage elements nowadays. It refers to the example of the wooden construction of Fatima Church in the small St. John community of the Cascavel municipality, in the interior of Paraná State, Brazil. This church was built in 1958, in a rural environment and, in 1987, and transferred as a monument to the urban area of Cascavel/PR.
\end{abstract}

Keywords: Place; Historical Heritage; Semiotic; Meaning; Cascavel-PR. 


\section{INTRODUÇÃO}

"Lugar" e patrimônio cultural são dois elementos importantes na formação da sociedade de qualquer Estado-Nação. Enquanto o "lugar" pode ser interpretado como um elemento (real ou fictício) que liga os indivíduos por meio de relações sociais e sentimentos de pertencimento a sua sociedade, o patrimônio cultural apresenta, por meio de sua materialidade, um "lugar" simbólico no qual se insere e expressa a historicidade e a sociabilidade dessa sociedade. Assim, a discussão sobre a função social do lugar e do "patrimônio histórico" é tanto uma questão de uma geografia individualizante, como ela se apresenta, por exemplo, na geografia humanista (TUAN, 1983; BUTTIMER, 1985; RELPH, 1976), como uma geografia social que pesquisa a produção de espaços sociais (GIDDENS, 2005; WERLEN, 2000; HAESBAERT, 2004). Perceber essa duplicidade entre forma e função social é de fundamental importância para o entendimento da formação do espaço social tanto no Brasil em geral, como nos seus estados e nas suas regiões, os quais, cada um por si só, apresentam formas diferenciadas de identificação e de identidades.

A recente e maciça história de imigração na região de Cascavel, desde os anos 1950, define-se por processos de identificação pouco enraizados e até às vezes "artificiais", características de regiões do avanço da frente pioneira, comuns no Brasil desde o final do século XIX quando se propagou uma política de imigração interna no país. Essa evolução culminou principalmente com a "Marcha para o Oeste" iniciada nos anos 1930 e a recente colonização da região amazonense e do Centro-Oeste. Por isso, o caso de Cascavel permite pesquisar processos de significação e de identificação típicos, a região estando ainda em fase inicial (duas gerações) de formação de identidades que influem na criação de valores sociais.

A formação de uma identidade passa não apenas por processos sociais e programas, políticos e culturais, mas também pela preservação e modificação de artefatos e objetos físicos que formam o palco desses processos com os seus referidos valores e significados. Neste contexto, são os próprios símbolos na sua existência material que permitem forjar uma identidade. Eles tornam-se instrumentos que agregam grupos sociais e regionais diferenciados, muitas vezes em diferentes escalas simultâneas. Assim, o patrimônio histórico não se refere apenas a uma sociedade em geral, mas, envolve outros processos identitários ao nível regional e local.

Num mundo de extrema mobilidade no qual se vive hoje no Brasil, percebe-se uma grande complexi- dade de valores e de sentidos o que traz consigo muitas vezes uma crise de identidade dos indivíduos, principalmente em relação à parcela do espaço que ocupam. Todavia, como asseguram Berger e Luckmann (2003), a identidade ainda deve ser vista como um elementochave na formação das realidades subjetivas, mesmo quando se problematiza a sua realidade com o espaço físico. A partir do momento que se cristaliza essa identidade, ela perpassa todo um complexo de manutenções, alterações a até remodelações em relação ao lugar em que esses processos se desenvolvem. Mas o que os ancora são os próprios artefatos que acompanham e refletem a formação e transformação da sociedade cultural.

Atualmente, o crescimento por vezes desordenado das cidades e a influência de um capitalismo quase onipotente no Brasil sufocam e até mesmo excluem do tempo presente (fluido) o passado (fixado) como testemunho vivo de todo um processo histórico local. Em muitos casos, a "memória urbana" no Brasil é substituída por um presente que se altera sucessivamente gerando novos significados (CARLOS, 1996). Dessa forma, o espaço urbano possui no seu processo de construção a característica de se focar mais em função de um tempo de passagem e de uma lógica de efemeridade, fato este que se traduz nos comportamentos e modos de vida de seus moradores. Esses, na situação de desenraizamento e de alienação, procuram controlar o tempo e o espaço na própria duração do uso, geralmente no sentido de uma sociedade funcional e capitalista. Desse modo, se esquecem muitas vezes das múltiplas pré-histórias (rede de fixos) que esses espaços já passaram dando abertura para uma homogeneização espacial fluida que traz consigo um esvaziamento dos significados históricos e individuais das múltiplas vivências. O cidadão comum é, então, impedido de vivenciar por meio do uso de espaços e pela visualização de imagens a apropriação das suas origens, ainda de outra época e de diferente consciência social, de uma auto-realização completa e identitária. Assim, o Patrimônio Histórico não é mais relevante e se perde como âncora nas formas urbanas. Precisa-se de uma re-valorização e re-apropriação do corpo urbano pela própria população por meio de uma cultura de enraizamento. Para Gutierrez (1989, p. 7) "a revalorização do patrimônio não visa apenas recuperar os significados emergentes dos monumentos, mas também resgatar a memória histórica da comunidade e recuperar valores de relação social e cultural", esses valores essenciais para a personalização do nosso povo afirmam a importância do conceito do "lugar".

"Lugar" é aqui, conforme Duarte (2002, p. 73), 
a formação de "uma porção de espaço, sem limites ou dimensões precisas, tendo sua riqueza na fermentação multiforme do processo de significação, que é de ordem cultural e não material". Processos de significação reproduzem, neste entendimento, processos materiais e imateriais que permeiam a sociedade. Por fazer parte da história coletiva, o lugar é amplo de significados, ou seja, a sensação de pertencer ao lugar traz em si um sentimento de vínculo emocional multiforme. Portanto, o lugar é essencialmente cultural e social. Ele se constrói pelo processo da significação horizontal, da organização e da hierarquização vertical dos elementos espaciais por meio do substrato cultural.

Este estudo objetiva, portanto avaliar o papel social do patrimônio histórico, não como simples objeto físico, mas como um valor de referência da sociedade e comunidade. Busca-se, conforme Gutierrez (1989), uma nova concepção da arquitetura e do urbanismo, uma visão cultural que ultrapasse o pensamento clássico de uma obra ou objeto como "objeto artístico ou cultural", como propuseram teóricos clássicos da arte como Wölfflin (1996) que ao final do século XIX compõe trabalhos dentro de uma abordagem psicológica da arquitetura, ou geógrafos como Carl Sauer na sua "Morfologia da paisagem" (SAUER apud CORREA, 2000). Este estudo quer projetar esses "objetos" no contexto das suas funções social e histórica. Para entender melhor os processos de significação, utilizam-se algumas abordagens semióticas, e as combinando-se com conceitos geográficos. A geografia semiótica surge na geografia, durante os anos 1980, com a Nova Geografia Cultural de D. Cosgrove (1984) e J. Duncan (1990) e consolidou-se por meio da grande obra de Paul Claval "A Geografia Cultural" (1995).

O nosso estudo de caso da Igreja Nossa Senhora de Fátima representa um exemplar destacado nesse sentido. Essa igreja, que é um modelo da arquitetura de madeira paranaense da década de 1950, foi originalmente localizada no Distrito São João D'Oeste do Município de Cascavel - PR, em que formou o centro arquitetônico de uma comunidade de agricultores de pequeno porte, elemento da sua vivência cotidiana. Posteriormente, ela foi demolida e reconstruída num Parque Público da Cidade de Cascavel, onde se tornou símbolo e signo da história dos pioneiros da cidade e, assim, um patrimônio histórico. Entretanto, a sua valorização e monumentalização, fora do seu lugar original, desencadeia uma problemática. Agora, ela passa a ser recontextualizada num ambiente completamente urbanizado e perde a sua função como templo religioso tornando-se um espaço cultural. Por isso, nesta pesquisa busca-se avaliar as mudanças das relações "sócio-semióticas" (GOTTDIENER, 1995) tanto dos pioneiros do Distrito São João D`Oeste a respeito da retirada da Igreja do seu sítio original e a sua posterior reconstrução fora desse contexto, como também dos atores políticos e a população da cidade que estiveram e estão presentes nesse processo de resignificação. $O$ recorte temporal adotado para estudo está delimitado entre a construção da Igreja pelos pioneiros, passando por sua reconstrução no Parque Paulo Gorski e se estende até os dias atuais para que se possa avaliar a sua função atual de ícone urbano.

O trabalho desenvolvido como tema de dissertação de mestrado em Geografia da UFPR organiza-se em três etapas distintas. Inicia-se com uma pesquisa das diferentes fases de compreensão do "lugar" como conceito para categoria de análise do saber geográfico. Essa categoria será investigada na interface entre Geografia Social e Cultural bem como nas ciências afins, pois se acredita que a relação indivíduo/patrimônio nasce de um processo cultural numa determinada sociedade e em dado momento histórico.

No pensamento da geografia cultural, entende-se o lugar como um espaço de relacionamento emocional e de significação. Para Duarte (2002), esse processo de significação é o meio pelo qual a sociedade impregna culturalmente os elementos formadores do Lugar, agregando signos e valores, para que esses então colaborem na identificação do indivíduo ou grupo no espaço em que ocupam. Por isso, a segunda etapa apóia-se nas ciências da Semiótica, Sociologia, Filosofia e Psicologia Social para que se possa verificar como e em que forma ocorre o processo de significação. As teorias vindas dessas ciências trazem o conceito da Significação, ou seja, procuram oferecer uma ferramenta para avaliar a mudança de valores, no nosso caso entre um elemento do cotidiano, uma Igreja, para um elemento de identidade local.

No estudo de caso da Igreja Nossa Senhora de Fátima parte-se na terceira etapa para uma análise que verifica algumas reflexões e hipóteses dos aspectos teóricos de investigação. Com o estudo desse objeto empírico queremos colaborar, além da discussão teórica sobre o entendimento do indivíduo para com a sociedade globalizada e a função do lugar e seus respectivos elementos formadores na sociedade moderna, na sensibilização da problemática do patrimônio numa "região nova" como essa do sudoeste paranaense.

Por meio da pesquisa empírica revelou-se que enquanto no passado, as paisagens e as sociedades 
forneciam sólidos referenciais de localização para os indivíduos, hoje eles podem ser efêmeros, virtualizados, falsificados e, assim, facilmente instrumentalizados. Desse modo, a relação identitária sofre grandes alterações e incertezas, e a fragmentação da sociedade e do seu espaço chega até a alterar a nossa própria individualidade, o que Hall (2005, p. 9) denomina de perda do "sentido de si". Sentimos, no corpo, a oscilação das idéias, a hegemonia do fluxo em cima do fixo, observamos a perda de estabilidades. Forma-se um processo de descentralização tanto do indivíduo como dos seus lugares sociais e culturais resultando numa crise de identidade vivida nos tempos atuais. Nesta reflexão percebemos, no fundo, que a identidade representa apenas uma relação que liga o indivíduo a uma estrutura estabilizante formando tanto o "sujeito" como o "lugar" em que ele vive. E é exatamente esse processo de unificação entre indivíduo e lugar que está sendo ameaçado permanentemente pelos processos de fragmentação pós-modernos. Esta análise pode revelar a importância de manter os patrimônios vivos em seu lugar de origem. São eles um dos responsáveis por ancorar o sujeito numa estrutura estável e colaborar assim para a intensificação do sentimento de identidade do indivíduo e o seu Lugar.

Neste artigo trazemos para o conhecimento da academia o encaminhamento metodológico adotado na pesquisa de campo bem como os resultados obtidos que formaram a base das conclusões alcançadas na dissertação intitulada "O Papel do Patrimônio Histórico na Construção do Lugar: A Igreja Nossa Senhora de Fátima em Cascavel - PR".

\section{COMUNICAÇÃO, CONVERSAS E ENTREVISTAS - UMA METODOLOGIA PARA SE ACHAR UM PA- TRIMÔNIO}

A abordagem acerca da memória segundo Tedesco (2001, p.13) envolve uma metodologia, a qual visa compreender a forma de análise do vivido em que se possibilita resgatar o tempo passado o fazendo presente por meio da análise oral. É a maneira de se construir e reconstruir formas de representação simbólica. Nesse processo de resgate do passado analisamos os relatos dos atores sociais de São João D'Oeste que foram silenciados ao longo do tempo. São eles que perpassam na sua história vivida o processo de transformação entre tradição e modernidade incorporando diferenças e complementaridades entre ambos e fornecendo significados culturais a essas duas categorias. O que chama atenção diante de nosso estudo de caso é o fato da retirada do bem histórico, fruto da construção dessa comunidade, do seu sítio natural e a sua inserção num novo contexto, agora fortemente monumentalizado. Conseqüentemente, essa transferência está acompanhada por processos semióticos que descontextualizam e recontextualizam o próprio bem em termos históricos. Trata-se de um problema comum para quase todas as políticas de preservação, que sempre são paralelamente políticas ideológicas, escolhendo determinadas visões sobre o passado e formando, assim, identidades imaginadas. Então, procuramos entender, embasado nas abordagens da Geografia Social e Cultural, como se constrói neste processo de semiose um espaço (lugar) nos moldes geográficos. Isso inclui a possível mudança de valores diante da situação pela qual passou a Igreja para os moradores de São João D'Oeste, para os atores que integram o estado, e por último para os cidadãos cascavelenses.

Para este fim executamos primeiramente entrevistas narrativas no período de setembro a outubro de 2006 coletando depoimentos de alguns pioneiros que continuam residentes no Distrito e formam a base de três famílias. Os depoimentos foram gravados para posterior interpretação. Essa técnica foi adotada para que os entrevistados possam relatar os fatos ocorridos de maneira natural e bem como expressar suas emoções e sentimentos em relação ao processo pelo qual passou a Igreja Nossa Senhora de Fátima. A intenção desse método foi a de investigar a visão dos pioneiros e interpretá-la por meio de processos hermenêuticos, identificando como se entende a construção da idéia do lugar e como se criou uma relação afetiva para com este destaque da paisagem rural. Foram feitas também perguntas sobre o atual sentimento de pertencimento dos entrevistados para com a igreja, agora denominada Igreja do Lago.

Após essas ações foram realizadas entrevistas com atores políticos de Cascavel que estavam no poder na época da relocação da igreja, investigando a questão da formação da identidade que envolveu a figura do estado e o seu entendimento. Questionamos também sobre outras razões por meio das quais se deu a transferência da igreja. A pesquisa foi ainda acompanhada por um questionamento a respeito das políticas públicas de preservação em geral em Cascavel, principalmente em relação aos processos de monumentalização do patrimônio. As entrevistas foram não-estruturadas e os entrevistados utilizaram seus próprios termos expressando assim os seus sentimentos.

Para alguns cidadãos cascavelenses foi feito um simples questionamento sobre a quem pertence a Igreja do Lago. A questão deu suporte para a análise da 
efetividade ou não dos processos de monumentalização pelo qual passou a Igreja Nossa Senhora de Fátima, atualmente Igreja do Lago.

Podemos caracterizar todas as entrevistas dentro de uma dimensão qualitativa possibilitando ao entrevistado responder com maior liberdade e sem constrangimento causados por perguntas pré-formuladas ampliando assim a dimensão das respostas. A principal diferença dessa forma de entrevista não-estruturada diante às demais é seu caráter aberto, deixando transparecer processos de significação e resignificação dentro da própria entrevista. Com base em idéias e significados que estão aglutinados na estrutura particular do entrevistado produz uma profundidade qualitativa dandoIhe um caráter de flexibilidade e descobrindo assim a desconstrução do profundo significado do processo investigado. Essa é a principal diferença dos métodos que padronizam as perguntas e preocupam-se em comparar as respostas limitando-as com um esquema pré-estabelecido (MAY, 2004, p. 149-150).

Dessa maneira, as entrevistas permitiram certa triangulação dos processos semióticos aos quais a Igreja Nossa Senhora de Fátima foi submetida durante a sua existência mostrando como os processos de resignificação influem também na construção e preservação do Patrimônio.

\section{IDENTIDADE LOCAL E MODERNIZAÇÃO - PERDA OU GANHO NA VIDA COTIDIANA EM SÃO JOÃO D'OESTE}

Nos dias de hoje, o município de Cascavel é visto, na sua atuação econômica, como um dos pólos mais dinâmicos do estado do Paraná preenchendo um dos requisitos principais de qualquer "modernização", o sucesso econômico entendido como inserção no processo capitalista por meio da integração nas redes comerciais do mundo do capital. Esse sucesso encontra sua expressão material no estilo de vida das pessoas que são afetadas por ele e, conseqüentemente, buscam certa "internacionalização" ou "americanização" nas suas expressões culturais. O processo de modernização está acompanhado, assim, por processos de significação responsáveis pela constituição de uma identidade que se reproduz em modificações materiais e imateriais, processos que envolvem e transitam em meio essa sociedade de "sucesso". Como a identidade de uma população passa, conforme as teorias semióticas de identidade, por momentos de construção e reconstrução adaptando-se a nova situação e criando formas de vínculos antes inimagináveis, esses proces- sos somam-se e produzem uma identidade coletiva a qual o caráter próprio e particular de cada comunidade reage. É importante salientar que cada processo de identidade (local ou não) e de construção do "lugar" é somado a uma nova inserção de atores que vêem agregando valores e mesclando suas formas de ser e de viver na região. Esses fatos de diversidade tornam o lugar mais rico de significados ao longo do tempo, mas dificultam também a coerência social porque resultam numa diversidade de códigos e numa fragmentação de uma identidade assumida.

Por isso percebe-se que os "atuais" pioneiros entrevistados do distrito nos relatam histórias que transitam em dimensões variadas quando optam verbalmente por resignificações desse passado, que eles não viveram. Caracteristicamente observa-se um processo de supressão de eventos anteriores pelos próprios "pioneiros" que só se reverte em alguns casos e só quando perguntados sobre pessoas que já moravam no local. Assim, a construção de uma identidade pioneira sempre começa com uma vida que teve início no momento (muitas vezes difuso) da posse do território.

Geralmente, se relata esse momento marcado pelas lutas cotidianas das famílias que chegaram e tinham que "limpar" o terreno, por meio do corte de árvores, a construção sofrida de estradas de terra, o grande esforço de plantar a roça, a precariedade das construções habitacionais etc. Tudo isso serve, como os "pioneiros" relatam, para mudar as suas vidas para melhor. Esse processo de resignifação por meio da atividade corporal representa indiretamente não só um distanciamento da história corporal da região de destino, mas também um distanciamento e até apagamento da própria biografia da família advinda quando joga ao esquecimento o passado anterior (geralmente em outra colônia em que se vivia com menos sucesso). Constróise, assim, um lugar "pioneiro" em que se pudessem fixar as raízes, contudo, isto acontece apenas depois de uma nova inserção de significados ao novo espaço material Para esse grupo pioneiro o "seu lugar" envolve uma aura simbólica de sonhos e de desejos que aos poucos foram sendo materializados. Importante salientar o valor da fé envolvida nesse processo, pois a cada entrevista podese presenciar o alto grau de angústias, questionamentos e dúvidas para esses pioneiros, que trabalham nas suas reflexões religiosas, criando um espaço imaginário fora das dificuldades do cotidiano material. Essa dimensão religiosa é capaz de agregar significados para os bens materiais que, portanto, não se pode ignorar e que projetam a igreja (como instituição e como edificação) central em sua função social e histórica. 
As experiências relatadas reforçaram na época os vínculos entre o grupo social e seu lugar, e essa união continua nas histórias contadas sobre as dificuldades da época, que hoje se resignificam e são lembradas como tempos em que a comunidade se unia diante de desafios e fortificava os laços com o seu espaço cotidiano. Essas reflexões nos trazem a essência dos processos de identidade pioneira aliados ao papel do patrimônio histórico e do lugar em si. As lembranças do passado são reconstruídas pelo grupo social tornandose assim fenômenos sociais que se apóiam na memória para dar consistência e perpetuação aos processos de significação ao longo do tempo. São as experiências concretas do vivido preenchido pela afetividade. Por isso, a presença da igreja era mais que um signo religioso em que se realizava a troca de relações e de experiências formou-se como um verdadeiro "lugar", em que os espaços humanizados uniram culturalmente os seus aspectos funcionais e simbólicos.

Portanto, no caso da igreja de São João D'Oeste pode-se verificar que o patrimônio histórico-cultural possui a capacidade de organizar lugares. Fornece a fixação necessária para que se expresse a identidade cultural dos indivíduos numa determinada materialidade e localidade. Trata-se, semioticamente, da construção e enunciação desse signo, que se preenche pelo significado.

Dessa maneira, podemos deduzir que, pelo menos nas teorias semióticas, a Igreja como objeto é um signo que possui a função de agregar no espaço em sua forma material e recebe o seu interpretante no seu conteúdo simbólico, ou seja, o significado original se transmite pela materialidade significante da edificação para outros significados conotativos ou interpretações. Esse signo direciona, portanto, também esse passado para um futuro correspondendo à memória de um grupo social que é a base de sua identidade.

No resgate da história vivida pelos pioneiros, observa-se principalmente entre os entrevistados da primeira geração, que para eles a Igreja do Lago continua sendo um patrimônio da comunidade do distrito São João D`Oeste, porque uniu a vida material e significante com os seus respectivos significados vividos. Mesmo hoje, quando a igreja não se encontra mais fisicamente presente, constitui sim um patrimônio local.

No entanto, o que chamou a atenção é que os filhos dos pioneiros nascidos em São João apenas possuem laços por assim dizer em "segundo grau" com a igreja, dado ao fato de serem inseridos em uma história que já se encontrava escrita. Não possuem esse mesmo sentimento de vínculo e pertencimento como seus pais, mesmo entendendo os seus significados emitidos. Para essa segunda geração a igreja é, nas palavras da entrevistada Maria "Piro" Mezzomo: “...outra igreja, não tem mais nada do que tinha antes!". Ela fala da igreja depois da sua transferência e faz alusão ao fato de que alterações realizadas na ação de deslocamento do bem cultural, como por exemplo, a perda da pintura interna e a diminuição de suas dimensões no novo local a tornaram já sem valor identitário para ela. As manchas no próprio signo também transformaram os seus significados.

Portanto, pode-se avaliar que o processo identitário e difundido ao longo do tempo quando se altera o ambiente sem que se perceba o exato momento de sua ruptura. Dessa maneira, a bagagem simbólica que o bem carrega numa dimensão subjetiva pode ser alterada quando não se consegue ancorar os seus valores originais. A história identitária conta, a partir desse momento, um falso histórico, em que a experiência vivida não coincide mais com a essência da experiência original. Mesmo se esse falso histórico é assimilado ao longo do tempo por meio de novos valores que são agregados e assumidos como verdadeiros para o seu significante, a identidade original nunca mais volta, como se percebeu por meio das entrevistas realizadas. O signo, no nosso caso da igreja, é um elemento do saudosismo de uma outra época.

Com isto podemos verificar que as representações, ou signos são entidades que permeiam o universo de um grupo social e se materializam em objetos e ações que são impregnados de sentido passados pelos indivíduos que pertencem a uma comunidade. Essa reprodução de um conteúdo material num conteúdo simbólico é vinculada à consciência em que a memória ganha intensidade, enquanto a vivência de outrora perde a sua força. No entanto para que se possa recordar esse conteúdo é necessário que ele seja interiorizado e incorporado pela consciência (imaterial), fato esse que não se vê presente na terceira geração do povoamento que não conhece mais a presença ativa da antiga igreja em ação.

A vida cotidiana em São João passou por vários momentos de modernização, mas posteriormente também de desvalorização de suas funções econômicas num processo econômico "pós-moderno". O movimento intenso da época em que se originou a comunidade já não existe mais, porém a comunidade local, diminuída em número de habitantes, agora possui como principal atividade a agricultura mecanizada e a pecuária. A riqueza dos pinheirais bem como as serrarias não estão mais 
presentes na vida do distrito, porque esse recurso de uma atividade extrativista se esgotou. Os pioneiros ainda residentes no local continuam suas atividades agrícolas, agora com menos intensidade, passando para as mãos dos filhos a sua herança. O centro de convivência ainda permanece com a presença de uma nova igreja, a Igreja de São João, o Salão comunitário, o Ginásio de esportes e a Escola Municipal. O Lugar São João, portanto, fornece para seus cidadãos as bases locais para que se construa uma nova identidade calcada por uma história múltipla de várias biografias. Percebe-se, contudo, que a não presença da Igreja Nossa Senhora de Fátima, ou seja, pelo menos na sua forma física acarreta aos poucos o seu esquecimento. Revela-se então a importância do patrimônio estar preservado em seu local original para que a comunidade não perca esse referencial sígnico. A perda do signifcante rompeu com os processos de semiose de um passado trazido para o presente.

\section{NA BUSCA DE UMA HISTÓRIA UNIFICADORA - MO- NUMENTALIZAÇÃO DO MODERNO E DO ANTIGO NA CIDADE DE CASCAVEL}

A intenção de se monumentalizar e criar um vínculo identitário para um objeto físico é o que motivou a transferência da Igreja Nossa Senhora de Fátima para o Parque Municipal Paulo Gorski, como relata o então prefeito Fidelcino Tolentino. Em entrevista com ele e outros atores políticos da época pôde-se perceber que a intenção primeira era o resgate da "história da região", numa maneira de tentar conscientizar a população que, segundo depoimentos, só vê o valor comercial embutido nos bens materiais. Esse comentário reproduz, implicitamente, que a "modernidade" - vivenciada por todos os entrevistados - não tem significado, enquanto o signo saudoso de outrora representa alguma coisa. Continuando nesse raciocínio, o ex-prefeito comenta na entrevista que a vida em comunidade possui um "ponto de convívio e convergência" e que os cidadãos do lugar "se protegem". Esse ponto de convergência, para ele, foi marcado pela presença física da igreja. Para ele, o patrimônio cultural representa, por meio dessa materialidade, um "lugar" simbólico no qual se insere e se expressa a historicidade e a sociabilidade unida da sociedade. É em torno dela que a vida se desenvolve e que as relações de transmissão cultural se efetivam. Diante desse pensamento ele buscou "preservar a imagem" num pensamento arquitetônico, tomando a forma como parte de uma "consciência que forma a identidade". Contudo, escapou a ele, como ao muitos que vivem em ambientes de fortes semioses de "moder- nização", que a transferência de um signo nem sempre leva todos os significados juntos. O código desse signo se constrói por meio de sua ambientação. Quando essa se perde, o que foi o caso da Igreja Nossa Senhora de Fátima que se tornou Igreja do Lago (até perdendo a sua santa como elemento simbólico nominal), o próprio signo se esvazia e só pode ser preenchido novamente com outros signficados.

Neste contexto, como visto anteriormente, a monumentalização de artefatos representa um caso específico. Como o monumento sempre lembra de influências de ações do passado no presente, essas quando não são mais exercidas por indivíduos em co-presença, perdem a sua ligação histórica. Já foram socializadas por membros antigos da sociedade, mas a "preservação" ou "remoção do contexto" de artefatos representa um tipo de rompimento para com as gerações passadas. As questões espaço-temporais apresentam-se no nosso caso como a "modernização" de uma sociedade, na sua rede múltipla, de extrema importância porque reproduzem padrões de vida anteriores no presente e formam um aspecto pós-moderno na multiplicidade dos espaços.

A função do Patrimônio - Igreja - já revelou na comunidade que os processos de significação são altamente problemáticos quando fazem parte da diferenciação e segmentação social de uma comunidade, como se percebeu nas atitudes diferenciadas entre as gerações para com o edifício. Signos, como esse, podem, sim, incluir, mas podem também alienar pessoas da própria história e da própria visão do mundo. Esse processo de diferenciação atua também no novo local da igreja, em que se necessita um amplo processo de conscientização do porquê da transferência e do novo valor desse Patrimônio, como esse não faz parte da história vivida do local, mas apenas de uma história assumida da região.

Até mesmo uma pessoa que consegue desenvolver uma identificação com um edifício cria um laço com esse objeto por meio de novas experiências vividas por ela (por exemplo, experiências estéticas como concertos, visitas turísticas, realização de saudosismos ligada às conversas com os idosos, etc.). Todavia, sem esforços de semiose, as pessoas até podem se sentir excluídas e alienadas desse lugar, por falta de possibilidades de identificar-se com ele. O mesmo edifício sendo significante na sua aparência adquire, dessa maneira, dois significados opostos, um de pertencimento e outro de alienação.

Verifica-se, portanto, o alto risco que as institui- 
ções correm ao tentar monumentalizar patrimônios sem ligação para com os moradores, e a Igreja do Lago não escapou desse perigo. Para a sua narrativa precisa-se de um amplo conhecimento histórico da própria região, do qual a esmagadora maioria da população não dispõe. Por isso, seria preciso a criação de um roteiro histórico regional que contextualiza-se (e justifica-se) a transferência da igreja. Um elemento desse relato poderia ser a antiga convivência com a madeira, típica do grande sucesso econômico até os anos 1980. Essa ligação se facilitaria ainda pelo fato que a árvore símbolo do Paraná (que é o conjunto político contextualizador do sucesso de Cascavel), faz parte de um imaginário coletivo vigente no estado. Esse imaginário até agora desprezou nas regiões ocidentais do estado, por causa da veneração do concreto modernizador que se apresenta nos prédios monumentalizados da cidade (Catedral, Praça do Migrante, Presas da Cobra), o antigo material tradicional, criando um rompimento (uma limpeza) com o passado que já se conhece das entrevistas com os pioneiros de São João D'Oeste.

O discurso pioneiro concretiza-se, literalmente, na cidade de Cascavel, o que faz uma igreja de madeira um Patrimônio, de primeira vista alienada e fora do contexto identitário. A divergência do passado pode, porém ser absorvida pelo presente e direcionar o futuro desejado dando um caráter de unificação ao universo simbólico. Escreve-se a História agora não como um passado oficial, mas com um potencial do futuro embutido em histórias. Forma-se, assim, uma unidade coerente a qual absorve o passado divergente, media o presente conflituoso e elabora um futuro desejado. Concreto e madeira, em suas diferentes expressões, deveriam fazer parte desse novo futuro social da sociedade cascavelense. Apenas quando se demonstra a contigüidade (até contraditória) dos dois materiais na história regional, se reestabelece uma função identitária da Igreja justificando o tombamento com Patrimônio histórico e cultural.

Em nosso caso, num primeiro momento os responsáveis pela transferência da igreja, todos de fora da comunidade de São João, possuíam a intenção de mantê-la no local de origem, monumentalizando-a como ponto de atração para futuros turistas. Essa ação não foi levada a diante pelo fato da própria comunidade local estar dividida sobre qual destino sería dado à igreja. Nessa disputa sobre o Patrimônio, venceram esses representantes "modernizadores" da própria comunidade que queriam "vender" a "madeira da igreja" para o município. Ignoraram, na disputa das identidades as insatisfações por parte de alguns pioneiros, que segundo o ex-prefeito eram vistos como "mais saudosistas e presos à história". Esse rompimento social dentro da comunidade servia para os próprios responsáveis da prefeitura como justificativa do seu ato, criando certa ironia no processo semiótico durante a preservação do patrimônio. Esperava-se pelos responsáveis que a sociedade urbana de Cascavel, que até então não tinha nenhum laço de convivência com essa igreja, desenvolveria mais laços identitários do que a própria comunidade dos construtores que se mostrava divida sobre o valor do edifício. Pergunta-se, se o saudosismo dos dirigentes do município não era ainda maior do que esses dos "atrasados" do distrito.

Enfim, á prefeitura cabia finalmente toda a responsabilidade do desmonte da igreja. Essa ação teve como premissa definida pelo órgão público o levantamento métrico e fotográfico para dar suporte à futura reconstrução. A escolha do local para a sua implantação ficou a cargo da arquiteta e urbanista Maria Angélica Vilasboas responsável por todo esse processo. E por decisão conjunta dos atores políticos de Cascavel foi destinada a sua reconstrução no parque municipal, fazendo parte de um corredor cultural da preservação de alguns elementos identitários da região. A partir desse momento, a igreja passa a ser propriedade do poder público e não mais da Igreja católica, ou seja, ela perde a função de local de culto passando a ser monumentalizada com o estigma de "Espaço Cultural". Completou-se a descontextualização e recontextualização, um processo muito comum na cultura moderna, sempre acompanhado por processos de desvalorização e revalorização monetárias. Nessa situação não-familiar, a cultura moderna busca incorporar a igreja e reinterpretá-la imediatamente por meio de um trabalho representacional para que assim seja restabelecido um sentido de estabilidade na sua identidade. Essa incorporação é ligada ao próprio trabalho cultural dos atores sociais de Cascavel, como veremos na sequência.

Nesse contexto, um dado importante é o fato de que dois mandatos de governo foram necessários para efetivar o processo de transferência que se iniciou em 1987 e concluiu-se em 1993. De acordo com depoimento revelou-se que a questão da ameaça da sua destruição, argumento original pela transferência, tornou-se um problema contínuo também depois desse momento. O material de madeira de lei, com alto valor sígnico numa região que já perdeu quase toda a sua riqueza natural quando se transformou em lucro econômico e, assim, justificou a auto-estima capitalista, era responsável para modificações que resultaram em "perdas" de algumas de suas características originais. Como o material empregado para a obra, madeira de 
Araucária angustifólia, requer uma constante manutenção para que não seja deteriorado, esse assunto sempre esteve presente nas entrevistas sobre o tombamento pelo município. Partindo da idéia de que se um bem é tombado não possui uma função definida, passa a correr riscos de se deteriorar e perder sua integridade física por falta de uso, esse patrimônio, de fato, não é patrimônio, mas símbolo alienado ou até vazio.

Pergunta-se, de onde nasce essa falta de consciência sobre o valor da própria história regional. Segundo entrevista, a alienação do "povo de Cascavel" se deve a um conflito entre uma consciência cultural e econômica, que se resolve em favor da segunda. Isso se reflete também no fato de, conforme as palavras de Fidelcino Tolentino, que alguns moradores "considerarem a igreja um Monumento estanque, só para mostrar a história". Esse "mostrar História" é, de fato, um caso problemático como a materialização de um elemento alheio pode criar uma desvalorização (tanto simbólica como material e até monetária) dos bens conquistados durante um processo de construção de identidade. Ganhar um patrimônio significa, por conseqüência, desencadear um processo que não se impõe, mas onde se conquista uma identidade que revaloriza e resiginfica elementos regionais antigos, mesmo quando aparecem em novos contextos. Essa identidade, sim, não é alienada, ela representa uma evolução extremamente lenta porque necessita de processos semióticos de constante formação de signos que precisam de tempo para se sedimentar nesses contextos comunicativos. Por isso, o saudosismo da própria gestão do então prefeito pode resultar, sim, numa recuperação desse bem raro, tornando-o caro, até em termos monetários por causa da sua manutenção. Entretanto, trata-se de um processo necessário e até, de certa forma, inevitável, numa sociedade que sempre reclama que vive sem uma identidade claramente definida e que se propaga como o moderno permanente sempre derrubando os seus próprios valores, como o fez, por exemplo, com as suas tão valorosas árvores e sua madeira, mas que também construiu um interessante e destacado acervo de arquitetura de concreto.

\section{O PATRIMÔNIO, UM CRUZAMENTO DE PERSPEC- TIVAS}

A identidade, como discutida anteriormente, é um processo de construção que incorpora a memória na formação de suas configurações e representações sociológicas, agregando valores e sentimentos culturais ao imaginário de uma sociedade desejada (não necessariamente existente). A re-apresentação desse imaginário ao longo da história fortalece o vínculo identitário com lugares que são "desenvolvidos" como patrimônio. Em nosso estudo, a Igreja Nossa Sra de Fátima foi construída na comunidade de São João D'Oeste, com a finalidade de ser o palco para a atuação desse grupo social. Quando foi transferida para outro local, perdeu essa função de estabilização social e afirmação da comunidade, mas essa mesma também já estava perdendo seu sentido graças a modernização. Nessa perspectiva, a materialidade da igreja, a madeira, já era vista como símbolo de atraso. É claro que um processo estabilizador desse tipo acompanha outras funções sócio-econômicas e identitárias muito mais profundas, como a individualização do homem moderno, a mecanização da produção agrária, a normatização das construções habitacionais pelos materiais industriais e a integração da população ao sistema de fiscalização do Estado, etc.

As entrevistas realizadas com os cidadãos cascavelenses vêm mostrando que esses processos são muito mais avançados no ambiente urbano, estabelecendo uma postura reflexiva entre as pessoas e até uma postura crítica para com o tradicionalismo estabilizador que resulta, entre outros, até na manutenção de um Patrimônio. Em particular dois depoimentos de entrevistados mostram essa visão crítica avançada em relação à representatividade do Patrimônio em análise. Confrontamos a seguir dois textos, em que os entrevistados apontam, em sua opinião própria, o que representa e a quem pertence a Igreja do Lago. Enquanto um respondeu: "Representa: Um elemento do cenário 'Lago'. Pertence: A ninguém, pois ninguém a usa", outro coloca: "Infelizmente a representatividade de divindades ou monumentos destinados à fé não significa muito para os cascavelenses".

Fazendo uma análise das respostas, fica evidente no caso do primeiro entrevistado a falta de apego ao Patrimônio em questão, principalmente em razão da deslocalização da edificação. Ainda, o mesmo entrevistado aponta, como o próprio prefeito já havia relatado, que a igreja é apenas um símbolo para "mostrar História". Lembrando que uma das funções básicas do Patrimônio Histórico na paisagem é a mediação de saberes sociais e históricos, fica claro que um saber histórico existe apenas para o governo municipal, enquanto o mesmo saber simplesmente não existe em relação à igreja para o entrevistado e, por isso, o patrimônio permanece sem ligação afetiva. Como a igreja ainda carece do uso cotidiano, não se oferece nenhuma função para estabelecer um sentimento de pertencimento o qual poderia desencadear um processo de identificação. 
Uma outra visão característica da cultura cascavelense é descrita pelo segundo entrevistado, quando aponta que a cultura local não se preocupa com as representações comunitárias e, assim, não consegue socializar as suas histórias diversificadas. Nesse sentido, a arquitetura, tanto tradicional como moderna, teria uma função importantíssima na fixação da identidade. Se considerarmos a arquitetura como um reflexo de uma sociedade e, conseqüentemente, como um signo que contém as marcas das suas histórias, ou seja, está impregnado de fontes do ser, do saber e do fazer de uma sociedade, o patrimônio "Igreja do Lago" passa a caracterizar uma representatividade local excluído do conjunto da cidade. Ela é simplesmente "de fora" e, por isso, não é vista pela comunidade como um marco de sua história. Esse fato, um pouco surpreendente, pode ser decorrente da cultura da colonização na região. A região foi constituída por uma intensa corrente de interesses particulares em que a "lei do mais forte" imperava tanto nas decisões políticas como sociais e até, por que não dizer, culturais. A grande maioria dos colonizadores que aqui chegaram tinha como meta construir o seu próprio império particular. Para isso, o foco de suas vidas era o crescimento material.

Esse orgulho de uma época extrativista e produtivista marcada pela devastação das florestas e pela violência gerada pela conquista de terras faz dos cascavelenses uma população que, na sua grande maioria, mostra-se orgulhosa por suas conquistas, porém, preocupa-se pouco com a preservação dessas conquistas. Assim, a posse do território, a conquista de terras, traz um sentimento de poder e de orgulho que gera um constante anseio em crescer cada vez mais e mostrar ao mundo que a região está em franco progresso, esquecendo do que já está consolidado. Assim, a igreja tornou-se obsoleta na própria comunidade e nunca ganhou ampla notoriedade na sua localização que se mostra "escondida" no cenário do lago. A falta de um eficiente sistema de proteção aos bens históricos é, também, um reflexo desse progresso individualista. Observa-se a necessidade constante de reproduzir no cenário urbano imagens ultra-modernas (contemporâneas) desprovidas de sua essência histórica e ideológica. Isso resulta finalmente numa uniformização das cidades modernas que é parcialmente responsável até pela destruição de símbolos físicos extraordinários que conformam a identidade.

Torna-se pertinente nesse momento relembrar que a cidade de Cascavel possui uma história relativamente recente que data do final do século XIX. Graças a essa curta relação espaço-tempo observa-se, em grandes partes da cidade, uma sensação de falta de pertencimento. Até hoje, a história da região é marcada por intensos fluxos migratórios tanto do sul (SC/RS) como do sudeste do país (MG/SP) o que se reflete também nos depoimentos que afirmam que Cascavel ainda busca encontrar sua identidade. A Igreja do Lago poderia ser um símbolo que colaboraria nesse processo de identificação, caso ela fosse integrada numa narrativa amplamente divulgada. Contudo, como são muitas as histórias biográficas, pelo fato da recente migração, poucas se interligam com a localidade, quer dizer tem pouco teor de "lugar", poderia ajudar apenas numa intensa participação social e comunicativa na recuperação da história da região. Só esse esforço seria capaz de recriar o passado do lugar para prover o presente condicionando o futuro. Por isso, necessita-se de uma ampla monumentalização da cidade que permita dar continuidade a diversidade e multiplicidade contextual da vida cotidiana das pessoas, a formação de signos múltiplos em termos regionais (e não locais).

Uma participação social, nas suas diversas dimensões, promoveria um enriquecimento da identidade espacial quando asseguraria a vitalidade do corpo social. Isso é possível quando se fortalece o acúmulo e a transmissão de conhecimentos que criam coesão social. No intuito de aperfeiçoar a identidade cultural podem ser feitas várias sugestões e propostas validas até para a superação das diversas dificuldades e obstáculos da vida cotidiana. Todavia, uma coerência da cultura local mais completa depende de uma grande amplitude de aceitação dos seus valores. Isso poderia garantir uma melhor fixação da estrutura equilibrada entre os seus membros. Esse desafio recorre a três dimensões geográficas ao mesmo tempo. A dimensão "raiz" deveria referir-se a história local e às vivências passadas que participaram na construção dos lugares da região. A dimensão "tecido" deveria juntar as interações dos moradores atuais, por exemplo, em eventos criados com criatividade para festejar a coesão social, inclusive eventos de saberes. Nessa dimensão recontextualiza-se a pluralidade das culturas de origem por meio de uma melhor legibilidade para o todo da sociedade. A dimensão "global" ainda deveria adequar a sociedade na sua funcionabilidade moderna (ou pós-moderna) garantindo a formação de um lugar regional no conjunto do estado moderno e até no mundo. Uma política cultural, inclusive uma política de preservação do patrimônio para buscar essa identidade, que respeita a multidimensionalidade e pluralidade identitária da região garantiria por meio de um maior transito semiótico entre todos os seus elementos, mesmo sendo esses contraditórios, uma coesão social. Traz, assim, os Monumentos para uma participação 
ativa no processo de mediação e organização espacial e identitária numa sociedade fragmentada.

Dessa maneira, a Igreja do Lago poderia marcar uma nova etapa de construção do "Lugar Cascavel", em que o "Patrimônio Histórico da Igreja" cumpriria a sua função social. A necessidade de criação de vínculos sociais resultaria numa identidade cultural que "localiza" identidades simbólicas múltiplas no espaço e no tempo. Nessa realidade, que hoje é vivida por Cascavel, precisa-se de uma política cultural forte e firme que recupera a auto-estima das pessoas por materializações. Ironicamente, os processos identitários de hoje envolvem mais que uma grande gama de relações e conflitos virtuais, sem materialização, embora estejamos vivendo numa época de materialismo puro.

A fluidez virtual-materialista pós-moderna cria o desejo de procurar um ambiente psicologicamente seguro induzindo uma paisagem de âncoras que se confrontam com as angústias flutuantes e a falta de identidades pessoalmente constituídas. Para superar essas incertezas surge o anseio de monumentalizar o Patrimônio Histórico e Cultural. Mas enquanto muitos vêm nisso uma atividade e até obrigação do estado, esquece-se muitas vezes a participação da consciência coletiva e da comunidade na construção desse patrimônio. O caso da Igreja do Lago é um caso típico nesse sentido. Sem participação popular, sem uma participação comunicativa em que se cruzam as mais diversas perspectivas sobre uma visão da própria sociedade não sobrevive nenhum Patrimônio.

\section{CONSIDERAÇÕES FINAIS: O PATRIMÔNIO CULTU- RAL E O SEU LUGAR PÓS-MODERNO}

O período moderno esteve caracterizado por concepções claras e definidas, tanto nas suas filosofias como nas suas formas de vivência. Desse modo, também a construção de espaços e lugares seguia a mesma norma e, conseqüentemente, as paisagens e as sociedades forneciam sólidos referencias de localização para os seus indivíduos. Provavelmente, os três elementos básicos das idéias normativas dessa fase histórica, a qual está se esgotando (mas ainda não terminou), representam o Estado-Nação, o indivíduo, além do desenvolvimento de uma lógica racional nãoambígua. Nos dias atuais, portanto, essas "certezas" se desfazem gradativamente e o mundo parece ser efêmero, virtualizado, até - às vezes - aparece falsificado. Uma fluidez permanente das nossas percepções e dos nossos signos substitui a ampla fase de fixação e, assim, faz os elementos sociais da época anterior facilmente instrumentalizáveis.

Assim, a relação identitária como processo de identificação é embutida na criação e resignificação de signos, de novas relações para com os espaços e para com os outros membros da sociedade. Portanto, o modelo antigo sofre grandes alterações e incertezas. A fragmentação da sociedade e do seu espaço chega até a alterar a nossa própria individualidade, o que Hall (2005, p. 9) denomina de perda do "sentido de si". Sentimos, no corpo, a oscilação das idéias, essa hegemonia do fluxo em cima do fixo, observamos a perda de estabilidades. Forma-se um processo de descentralização, uma explosão tanto do indivíduo como dos seus lugares sociais e culturais resultando numa forte crise de identidades vividas nos tempos atuais. Percebemos, no fundo, que a identidade (moderna) que formou indivíduos os quais não eram divisíveis, etnias que foram naturalizadas como tribos, e nações que se denominaram hegemônicas em relação aos indivíduos e tribos, até para com outras nações, representou apenas uma relação provisória que liga o indivíduo a uma estrutura estabilizante formando tanto um "sujeito" como um "lugar" em que ele vive. Contudo, é exatamente esse processo de unificação entre indivíduo e lugar que está sendo ameaçado pelos processos de fragmentação pós-modernos.

A idéia e a presença de patrimônios foi fundamental nessa construção de identidade embutida no lugar. Desde o século XVIII, a época moderna monumentalizou certo acervo de edificações e obras artísticas que discutiram e afirmaram as identidades da sua respectiva época, gerando âncoras para que se fixasse o indivíduo em uma estrutura fornecendo a base da sua identidade. Falar de patrimônio é, portanto também falar da vida cotidiana, em que esse processo se efetua para o individuo, em que ele se subjetiva. Essa identidade moderna foi alicerçada nos objetos, nas crenças, nos hábitos, modos de ser e de fazer de toda uma comunidade que possui um espaço particular em que as práticas cotidianas se desenvolvem reforçando os laços culturais. Isso resultou na formação de lugares de monumentalização, como museus, teatros, monumentos e edificações singulares, além das monumentalizações pequenas do cotidiano, como o altar no canto do quarto, a festa tradicional, o traje, etc.

Hoje construímos nosso espaço por meio de um modo de produção capitalista, em que os objetos no seu valor de uso transformam-se em objetos com valor de troca. Por isso, o objeto não permanece mais no seu lugar, mas é trocado por outro objeto, diminuindo assim a força dos contextos semióticos desses objetos. As 
cidades como grandes centros de comercialização são os promotores principais desses processos. Nos seus espaços de relações se produzem identidades fragmentadas, diminuindo o papel do indivíduo em favor de um indivíduo heterogêneo. Como Charles Baudelaire havia ressaltado nos seus textos do século XIX, quando Paris tornou-se o primeiro modelo dessa nova urbanidade, o sujeito urbano torna-se flaneurs, relegando ao sujeito a mera função de espectador da vida cotidiana.

Observamos uma facilidade social em construir um novo espaço urbano que representa a justaposição de dimensões espaço-tempo, de dimensões sociais, políticas, econômicas e de religiões, o que retrata um espaço de contradições. Essas contradições são, sim, fruto da lógica capitalista, mas também da individualização dos sujeitos, do questionamento das relações sociais tradicionais e até da multiplicação de códigos de comunicação. A constante construção e reconstrução do espaço urbano é o que destrói os laços antigos das identidades modernas bem como acaba com a certeza das interpretações para com os símbolos físicos da identidade no espaço urbano. O espaço rural apresenta, nesse conjunto, uma função específica que contrasta com a fluidez urbana. Sem esse contraste, a nova formação de semi-identidades pós-modernas não funcionaria porque enraizaria o indivíduo fora de sua realidade. Por isso, a imagem do rural como semi-natural, ou a imagem da origem, como é expresso no mito do pioneiro, são imagens norteadores nas confusões do cotidiano. Elas não existem no sentido de que fazem parte da existência vivida das pessoas, mas dispõem de uma existência essencial no fundo dos desejos e anseios das pessoas. Por isso, a construção de um patrimônio é fundamental, não como preservação do histórico "autentico", mas do humano existencial (mesmo inventado) que nos da sentido.

Assim sendo, este trabalho teve como objetivo maior chamar a atenção para essa necessidade de se preservar o Patrimônio Histórico numa situação pósmoderna. Numa sociedade que é fortemente formada por um discurso hegemônico das elites (que utilizaram e até utilizam a construção da modernidade, com todo o tradicionalismo que isto inclui, como ferramenta de dominar), as culturas populares, inclusive as rurais, têm um papel fundamental, porque representam o outro numa fase de fluidez modernizadora. Por isso, a Arquitetura Vernacular da região de Cascavel - PR carente de atenção necessita de ações que promovam a sua preservação. Pela lógica do mercado, o patrimônio só merece ser preservado se nele se encontrar embutido um valor econômico. Portanto, as lógicas de aumento e diminuição do preço seguem as lógicas sociais que definem culturalmente o que é valorizado ou não valorizado. Por isso, o problema não está no mercado capitalista, mas na consciência das pessoas. Quando o patrimônio for valorizado, será também economicamente caro e procurado no mercado.

Por isso, a falta de uma visão preservacionista que pode levar à extinção dos "bens históricos locais" se deve a uma ideologia modernizante que desconsidera a integração social dos bens históricos e culturais. A arquitetura em madeira, característica dos imigrantes pioneiros de nossa região, está sendo devastada no meio urbano, porque recebeu uma resignificação de pobreza e atraso graças à chegada de novas formas e materiais de construção. Depois que as matas paranaenses foram devastadas em prol de um suposto progresso, a história da região passou por momentos de ascensão econômica na década de 1930 a 1940 ao nível estadual e nacional, tornando os elementos culturais de fora tão importantes como os elementos locais. A vinda dos imigrantes do sul do país para o Paraná contribuiu ainda mais para a importação e valorização de elementos alheios da região. Construíram uma vida nova que se baseou na implantação dos seus anseios de modernização seguindo exatamente a lógica modernizante na qual o indivíduo é o dominador das suas escolhas, e não um ser social conservador e tradicional que preserva o que outros tinham utilizado para formar uma região. No período dos anos 1950 e 1960, os pioneiros, principalmente esses do sul do país, finalmente conseguiram construir a sua cidade "moderna", com ruas asfaltadas, prédios modernos de concreto, aço e grandes superfícies de vidro, atrair grandes lojas e supermercados etc. formaram uma arquitetura que até hoje apresenta uma identidade efêmera, migratória desses imigrantes. As antigas técnicas construtivas, portanto, aliadas à abundância da madeira, tornaram-se uma arquitetura peculiar, quase exótica, que não acompanhou tanto na sua estética como no seu valor econômico essa evolução. Nesse momento, entretanto, os imigrantes agora fixados sentem, pelo menos inconscientemente, falta de uma história contínua e identitária, sendo atirados num ambiente inóspito, alheio, sem poder traçar a sua própria história vivida. Por isso, observamos hoje a chegada da monumentalização do passado (da região, mas eventualmente também da história dos imigrantes), enquanto a monumentalização da modernidade arrasadora torna-se mais e mais criticada.

Insere-se nesse processo a preservação da igreja do Lago, um patrimônio que passa por um processo de resignificação sendo monumentalizado num período 
pós-moderno em que a fluidez de uma identidade sugere a busca por uma segurança psicológica. Reforça-se assim a importância da presença desse bem material para que, dentro de sua semiose, sirva de âncora e que permita conduzir a diversidade de contextos na formação de um signo regional garantindo assim a construção de uma identidade que possa unificar o indivíduo ao seu Lugar.

\section{REFERÊNCIAS}

BERGER, Peter L.; LUCKMANN, Thomas. A Construção Social da Realidade. Petrópolis: Ed. Vozes, 2003.

BRANDI, Cesare. Teoria da Restauração. Cotia-SP: Ateliê Editorial, 2004;

BUTTIMER, A. Aprendendo o dinamismo do mundo vivido. In: CHRISTOFOLETTI, Antônio C. (Org.). Perspectivas da geografia. São Paulo: Difel, 1985.

CARLOS, Ana Fani A. O Lugar no/do Mundo. São Paulo: Ed. HUCITEC, 1996.

CLAVAL, Paul. A Geografia Cultural. 2. ed.,Florianópolis: UFSC, 2001.

CORREA, Roberto L.; ROSENDAHL, Zeny. Geografia Cultural: Um Século (1). Rio de Janeiro: EDUERJ, 2000.

COSGROVE, Dennis. Mundos de significados: Geografia cultural e imaginação. In: CORRÊA, Roberto L.; ROSENDAHL, Zeny (Orgs.). Geografia cultural: um século (2). Rio de Janeiro: UERJ, 2000.

DUARTE, Fábio. Crise das Matrizes Espaciais. São Paulo: Perspectivas, FAPESP, 2002.

DUNCAN, James. A paisagem como sistema de criação de signos. In: ROSENDAHL, Zeny; CORREA, Roberto L. (Orgs.).
Paisagens, textos e identidade. Rio de Janeiro: EDUERJ, 2004.

GIDDENS, Anthony. As Consequências da Modernidade. São Paulo: Editora UNESP, 1991. Sociologia. Porto Alegre: Artmed, 2005.

GOTTDIENER, Mark. Postmodern Semiotics. Material Culture and Forms of Postmodern Life. Cambridge: Blackwell, 1995.

GUTIÉRREZ, Ramón. Arquitetura Latino-Americana. São Paulo: Nobel, 1989.

HAESBAERT, Rogério. O mito da desterritorialização: do "fim dos territórios" à multiterritorialidade. Rio de Janeiro: Bertrand Brasil, 2004.

HALL, Stuart. A Identidade Cultural na Pós-modernidade. Rio de Janeiro: DP\&A, 2005.

MAY, Tim. Pesquisa Social. Questões, métodos e processos. Porto Alegre: Artmed, 2004.

RELPH, Edward. Place and Placelessness. London: Pion, 1976.

SANTOS, Milton. A Natureza do Espaço, técnica e tempo/ razão e emoção. São Paulo: Ed. HUCITEC, 1997;

TEDESCO, João Carlos. Memória e cultura, o coletivo, o individual, a oralidade e fragmentos de memórias de nonos. Porto Alegre: Edições EST, 2001.

TUAN, Yi Fu. Espaço e lugar. São Paulo: Difel, 1983.

WERLEN, Benno. Regionalismo e sociedade política.Universidade Friedrich-Schiller, Jena (Alemanha). Tradução: Rogério Haesbaert. Revisão: Wolf-Dietrich Sahr. Revista Geographia, ano II, n. 4, 2000.

WÖLFFLIN, Heinrich. Conceitos fundamentais da história da arte. São Paulo: Martins Fontes, 1996. 
